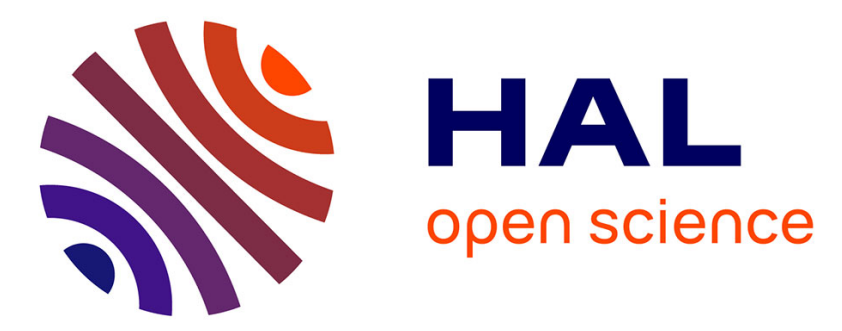

\title{
NEMS Devices for Accelerometers compatible with thin SOI technology
}

E. Oiller, L. Duraffourg, M.T. Delaye, H. Grange, S. Deneuville, J. Bernos, R. Dianoux, F. Marchi, D. Renaud, T. Baron, et al.

\section{- To cite this version:}

E. Oiller, L. Duraffourg, M.T. Delaye, H. Grange, S. Deneuville, et al.. NEMS Devices for Accelerometers compatible with thin SOI technology. IEEE International Conference of Nano/Micro Engineered and Molecular Systems, Jan 2007, Bangkok, Thailand. pp.1078-1083, 10.1109/NEMS.2007.352257 . hal-00534005

\section{HAL Id: hal-00534005 \\ https://hal.science/hal-00534005}

Submitted on 20 Apr 2021

HAL is a multi-disciplinary open access archive for the deposit and dissemination of scientific research documents, whether they are published or not. The documents may come from teaching and research institutions in France or abroad, or from public or private research centers.
L'archive ouverte pluridisciplinaire HAL, est destinée au dépôt et à la diffusion de documents scientifiques de niveau recherche, publiés ou non, émanant des établissements d'enseignement et de recherche français ou étrangers, des laboratoires publics ou privés. 


\title{
NEMS Devices for Accelerometers Compatible with Thin SOI Technology
}

\author{
E. Ollier ${ }^{*}$, L. Duraffourg ${ }^{1}$, MT. Delaye ${ }^{1}$, H. Grange ${ }^{1}$, S. Deneuville ${ }^{1}, J$. Bernos ${ }^{1}$, R. Dianoux ${ }^{2}, F$.

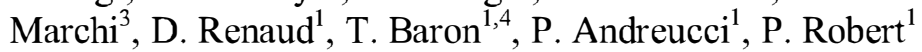

\begin{abstract}
The paper presents Thin SOI NEMS structures for accelerometers based on Thin SOI technology and compatible with "In-IC" integration. Modeling of Casimir force, design of accelerometers, improvement of hybrid e-beam/DUV lithography and FH-vapor release, development of specific AFM characterizations have allowed to fabricate NEMS devices and to provide AFM characterizations.
\end{abstract}

\section{Index Terms - integration, NEMS, SOI, accelerometer}

\section{INTRODUCTION : INTEGRATION AND NEMS}

A lot of MEMS are fabricated with stand-alone approaches even if an ASIC is generally provided in order to ensure driving and signal processing. Nevertheless, integration has been considered for several years. In addition to other integration strategies, SoC (System on Chip) approach is extensively investigated and leads to vertical or horizontal architectures enabling integration of MEMS and IC. Vertical integration tends to realize the integration at the substrate level, the interconnection level, the above-IC level or the module level. Horizontal integration allows to integrate the MEMS and the IC on the same surface. Monolithic integration of MEMS and microelectronics on thick SOI wafers has already been reported, the MEMS being manufactured before or after the CMOS.

Thin SOI technology is capable to push forward the possibilities by offering the ability to provide horizontal integration directly at the front-end level. Thin SOI technology means thin silicon top layer, for example $160 \mathrm{~nm}$ thickness if we consider the $0.13 \mu \mathrm{m}$ CMOS SOI technological node. The idea is to use this thin silicon layer, traditionally dedicated to the CMOS process, for the MEMS fabrication (Fig.1). The first consequence is that at least one dimension of the MEMS structure is shrinked to the nanoscale. As a consequence the mechanical device must be considered as a NEMS (Nano-Electro-Mechanical Systems).

\footnotetext{
${ }^{1}$ CEA/LETI - 17 rue des Martyrs 38054 Grenoble Cedex 9 - France

${ }^{2}$ ESRF - B.P. 220, 38043 Grenoble cedex 9 - France

${ }^{3}$ CNRS/LEPES, 25 avenue des Martyrs, 38042 Grenoble Cedex 9 - France Université Joseph Fourier, B.P. 53, 38041 Grenoble Cedex 9 - France

${ }^{4}$ STMicroelectronics - 850 rue Jean Monnet, 38926 Crolles - France

*Corresponding author: Eric Ollier, Tel : 33438785735 , Fax : 33438785169 , e-mail : Eric.Ollier@,cea.fr
}

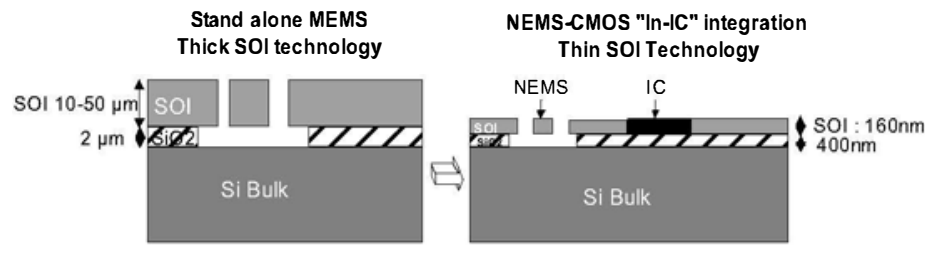

Figure 1. From MEMS devices to NEMS devices on Thin SOI substrate

Despite the technological difficulties arising, this constrain can also be considered as an opportunity to benefit from the attributes of NEMS. Indeed, NEMS (Nano-Electro-Mechanical-Systems) devices are emerging as a new field with a great deal of interest because they offer in the same time compatibility with "In-IC" integration and also very interesting specific advantages such as potential ultra miniature size elements, low power consumption, potential high resonant frequencies and quality factors, fast response time, high sensitivity to applied force, external damping or additional mass. As a consequence, NEMS are very promising for ultimate sensing, autonomous sensors, battery-operated systems and can allow new architectures. Nowadays, NEMS are investigated in order to face the challenges of nano-world and have a better understanding of the fundamental issues of mechanics in the nano-scale [1]. But thanks to the combination of powerful attributes such as unprecedented mass sensitivity and high operational resonance, NEMS opens up the possibility to prospect ultimate inertial mass sensing [2]. Resonant NEMS can also be combined with nanoelectronic [3] to fabricate displacement detectors based on RF-SET (Radio-Frequency Single-Electron Transistor). NEMS-IC integration is highly suitable since it can enable to decrease the cost of MEMS. In addition, good performances can be expected because the proximity between NEMS and IC enables to suppress a lot of parasitic effects. In particular, thin SOI technology is a very good candidate since the same thin layer of single-crystal silicon can be used for both mechanical structures and advanced ICs.

In particular, this approach can be attractive for low cost accelerometers for applications such as: hard-drive protection, motion interface for cell phones, handheld PDAs, game controllers and also gesture recognition or motion capture for medical, wellness or sports activities [4]. 


\section{MODELING AND DESIGN}

50G and 10G accelerometers have been designed in two configurations: In-Plane (IP) accelerometers with sensitive axis included in the plane of the wafer, and Out-of-Plane (OOP) accelerometers with sensitive axis perpendicular to the wafer (Fig.2). An acceleration causes the motion of a proof-mass and the corresponding displacement is measured by means of a variation of capacitance between two sets of electrodes. The electrodes are either interdigitated combs (IP) or two parallel plates (OOP).

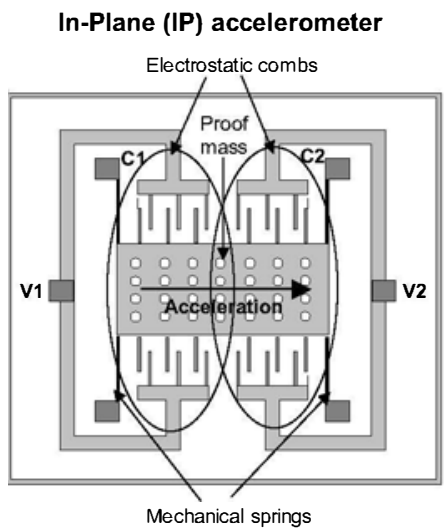

Out-of-Plane (OOP) accelerometer

Figure 2. Principle of IP (In-Plane) and OOP (Out Of Plane) accelerømeters

If we consider $0.13 \mu \mathrm{m}$ CMOS SOI technology, the first constrain to take into account is the $160 \mathrm{~nm}$ thickness of the silicon top layer that will be used for the NEMS and MEMS structures. In order to avoid parasitic deformations and undesirable vibration modes, the mass size has been limited to typical dimensions of $75 \times 150 \mu \mathrm{m}$ and $100 \times 100 \mu \mathrm{m}$, respectively for IP and OOP accelerometers. As a consequence the mass is about 4ng. In addition, for IP accelerometers, low cross-sensitivity implies to increase the ratio thickness/width of the mechanical springs, leading to $50 \mathrm{~nm}$ wide mechanical springs. In the same time, increase electrical sensitivity means decrease electrostatic gap down to $100-400 \mathrm{~nm}$. Finally, depending on the acceleration range and the resolution expected, the length of mechanical springs and the number of teeth of the electrostatic comb have been adapted. Typically, the length of springs and electrostatic teeth range from 1 to $10 \mu \mathrm{m}$. For OOP accelerometers, the electrostatic gap is fixed by the $400 \mathrm{~nm}$ BOX thickness. The mechanical springs are typically a few micrometer wide and $10 \mu \mathrm{m}$ to $100 \mu \mathrm{m}$ long depending on the acceleration range. The mechanical stiffnesses investigated in this study range from $10^{-2}$ to $0.3 \mathrm{~N} / \mathrm{m}$. The resonance frequencies are respectively about 10 to $20 \mathrm{KHz}$ for IP and OOP accelerometers.

Because of thin SOI technology, some dimensions have been reduced drastically compared to traditional thick SOI technology and are now situated in the nano-scale, in particular the mechanical spring width $(50 \mathrm{~nm})$ and the electrostatic gaps $(100-400 \mathrm{~nm})$. As a consequence, the role of specific phenomenon occurring in the nano-scale has been studied, in particular the role of quantum non-gravitational attraction named Casimir force. This force occurs at intermediate distances, between Van der Waals forces and electrostatic forces and can be attractive or repulsive depending on the conditions. A novel model has been developed for silicon devices in order to take into account doping level and dimensional effects. A corrective factor $\eta=F c / F i$ is applied in the commonly used formulas established assuming parallel metal plates [5]. Fc is the corrected Casimir force, Fi is the ideal Casimir force assuming two uncharged infinite parallel plates with perfect conductivity. Fig.3 illustrates the effect of doping level and slab thickness on the corrective factor. These simulations show that silicon structures, even highly doped, allow to reduce the impact of Casimir force on the device behaviour compared to the ideal case with electrodes constituted of metal.

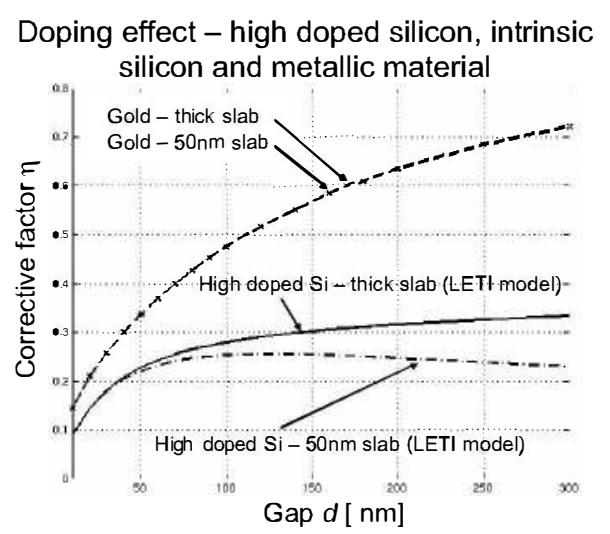

Figure 3. Effect of doping level and slab thickness on Casimir corrective factor

Based on this model, 50G accelerometers have been designed in both IP and OOP configurations. IP50G accelerometers are constituted of a $75 \mu \mathrm{m} \times 150 \mu \mathrm{m}$ proof mass, electrostatic combs with teeth $80 \mathrm{~nm}$ wide and gaps $130 \mathrm{~nm}$ to $400 \mathrm{~nm}$ wide. With $130 \mathrm{~nm}$ gap, the mechanical spring is $50 \mathrm{~nm}$ wide and $4 \mu \mathrm{m}$ long. With $400 \mathrm{~nm}$ gap, the mechanical springs are $50 \mathrm{~nm}$ wide and $11 \mu \mathrm{m}$ long. OOP accelerometers are constituted of a $100 \mu \mathrm{m} \times 100 \mu \mathrm{m}$ proof mass with an electrostatic gap $400 \mathrm{~nm}$ wide. The mechanical springs are $10 \mu \mathrm{m}$ wide and $80 \mu \mathrm{m}$ long.

It has been demonstrated that the architecture has a strong influence on the impact of Casimir force. In particular, relative large gap and small tooth width minimize Casimir effect. As a consequence, a trade-off must be found between high sensitivity and low Casimir effect. Indeed, to reach better sensitivity, the flexure stiffness and/or the gap between two adjacent teeth must be decreased, but, in that case, Casimir impact tends to reduce the pull-in voltage, increase the capacitance variation and induce larger non-linearity. Fig.4 shows displacement/acceleration curves including the effect of Casimir force for IP-50G accelerometers, respectively for $130 \mathrm{~nm}$ and $400 \mathrm{~nm}$ gaps. This figure illustrates that for IP accelerometers, large gap (400nm) ensures negligible influence of Casimir force, but for smaller gaps $(130 \mathrm{~nm})$, the impacts have quickly to be considered. 

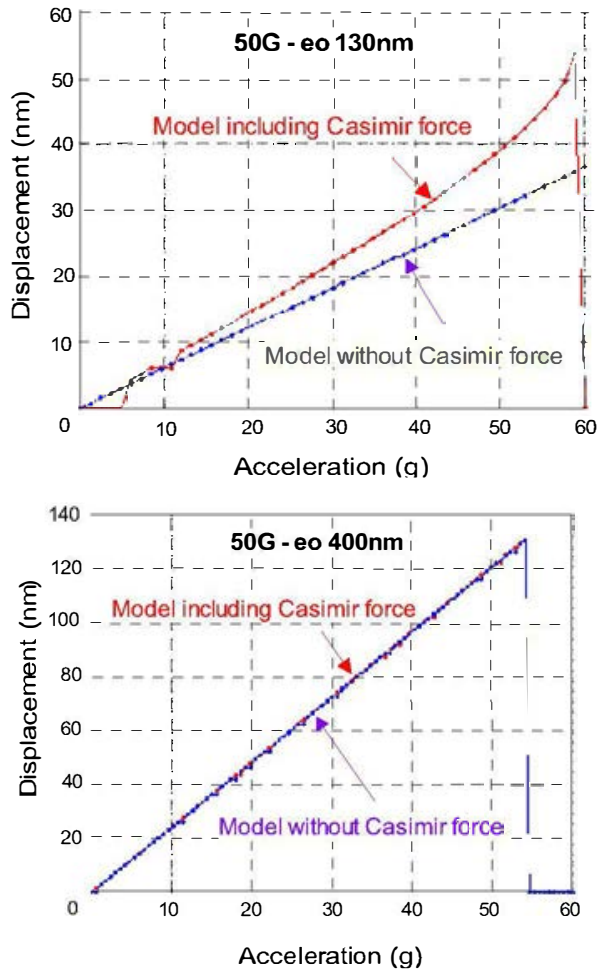

Figure 4. Displacement/acceleration curves for IP $50 \mathrm{G}$ accelerometer with respectively $130 \mathrm{~nm}$ and $400 \mathrm{~nm}$ gap (Influence of Casimir Force)

Fig.5 and 6 give expected mechanical and electrical performances respectively for IP-50G and OOP-50G accelerometers.

\begin{tabular}{|c|c|c|c|}
\hline \multicolumn{2}{|l|}{ Mechanical results } & \multicolumn{2}{|l|}{ Mechanical results } \\
\hline Weigth $(\mathrm{Kg})$ & $4,10 \mathrm{E}-12$ & Weigth $(\mathrm{Kg})$ & |4,10E-12 \\
\hline Stiffness $(\mu \mathrm{N} / \mu \mathrm{m})$ & 0,07 & Stiffness $(\mu \mathrm{N} / \mu \mathrm{m})$ & 0,017 \\
\hline Mechanical sensitivity $(\mathrm{nm} / \mathrm{g})$ & & Mechanical sensitivity $(\mathrm{nm} / \mathrm{g})$ & 2,4 \\
\hline Electrical results & & Electrical results & \\
\hline Pull-in voltage $(\mathrm{mV})$ & 220 & Pull-in voltage (V) & 1,45 \\
\hline Pull-in displacement $(\mathrm{nm})$ & 52 & Pull-in displacement (nm) & 133 \\
\hline $\mathrm{Co}(\mathrm{fF})$ & 7,3 & Co (fF) & 0,89 \\
\hline C full range (50G) (fF) & 3,25 & C full range $(50 \mathrm{G})(\mathrm{fF})$ & 0,4 \\
\hline Electrical sensitivity (aF/g) & 60 & Electrical sensitivity (aF/g) & 8 \\
\hline
\end{tabular}

Figure 5. Expected performances of IP 50G accelerømeters (130nm-400nm ga p)

\begin{tabular}{|c|c|}
\hline \multicolumn{2}{|l|}{ Mechanical results } \\
\hline Weigth $(\mathrm{Kg})$ & $3,64 \mathrm{E}-12$ \\
\hline Stiffness $(\mu \mathrm{N} / \mu \mathrm{m})$ & 0,017 \\
\hline Mechanical sensitivity $(\mathrm{nm} / \mathrm{g})$ & 2,6 \\
\hline \multicolumn{2}{|l|}{ Electrical results } \\
\hline Pull-in voltage $(\mathrm{mV})$ & 110 \\
\hline Pull-in displacement (nm) & 110 \\
\hline Co (fF) & 55,3 \\
\hline${ }^{\circ} \mathrm{C}$ full range $(50 \mathrm{G})(\mathrm{fF})$ & 28 \\
\hline Electrical sensitivity $(\mathrm{aF} / \mathrm{g})$ & 540 \\
\hline
\end{tabular}

Figure 6. Expected performances of OOP $50 \mathrm{G}$ acceler॰meters (400nm ga p)

IP accelerometers exhibit pull-in voltage from a few $100 \mathrm{mV}$ to $1.5 \mathrm{~V}$ respectively for $130 \mathrm{~nm}$ and $400 \mathrm{~nm}$ gap width. FS capacitance change is $3.5 \mathrm{fF}$ down to $0.4 \mathrm{fF}$ respectively for $130 \mathrm{~nm}$ and $400 \mathrm{~nm}$ gap width. OOP accelerometers exhibit driving voltage about a few $10 \mathrm{mV}$ to $100 \mathrm{mv}$ and FS capacitance change around a few $10 \mathrm{fF}$. The sensitivities are respectively in the ranges of $10-100 \mathrm{aF} / \mathrm{g}$ and $500-1000 \mathrm{aF} / \mathrm{g}$ for IP and OOP accelerometers. These figures are far from conventional MEMS but can be considered as acceptable considering the fact that ultra low noise CMOS ICs are capable to resolve better than $1 \mathrm{aF} / \mathrm{sqrt}(\mathrm{Hz})$ of capacitance variation. Moreover NEMS structures developed with "In-IC" integration approach will benefit of reduced parasitic capacitances allowing to expect to resolve $10^{-3} \mathrm{aF} / \mathrm{sqrt}(\mathrm{Hz})$.

\section{THIN SOI FABRICATION}

The fabrication of NEMS devices and accelerometers (Fig.7) is based on Thin SOI $130 \mathrm{~nm}$ technology and $200 \mathrm{~mm}$ facilities. The Si top layer is $160 \mathrm{~nm}$ thick and the BOX oxide is $400 \mathrm{~nm}$ thick.

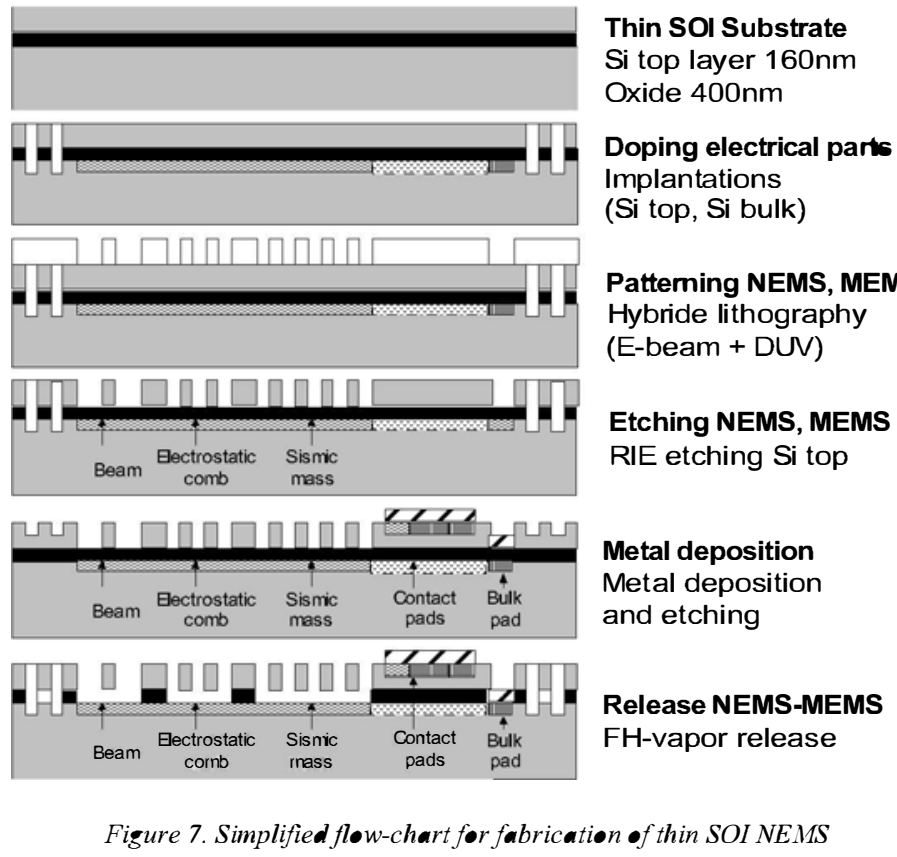

Scaling considerations have been addressed in order to realize on the same wafer the nano-structures (springs, electrostatic combs) and the large structures (proof mass, electrical pads...). To reach this goal, hybrid lithography combining advanced UHR e-beam and 248nm DUV lithographies has been used. In addition, FH-vapor technique has been improved to enable the release and protection against sticking despite the $500 \mathrm{~nm}$ diameter of the release holes and the $400 \mathrm{~nm}$ thickness of the sacrificial oxide. Finally, AlSi metal was used for electrical pads.

These technologies have allowed to manufacture different NEMS structures such as thin mechanical beams, large mechanical structures like membranes of rigid masses and also narrow gaps 
for electrical purposes. Fig. 8 illustrates how these technologies are used and highlights a few results obtained. In particular, mechanical beams $50 \mathrm{~nm}$ wide and electrostatic gaps $100-400 \mathrm{~nm}$ wide have been manufactured (Fig. 9).

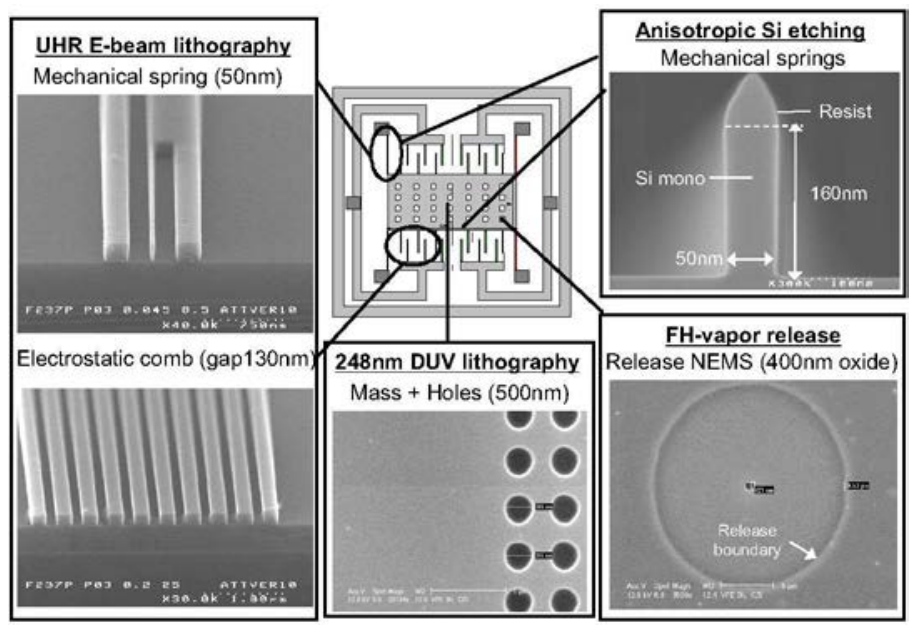

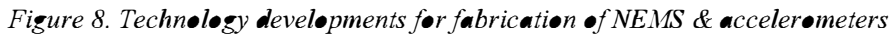

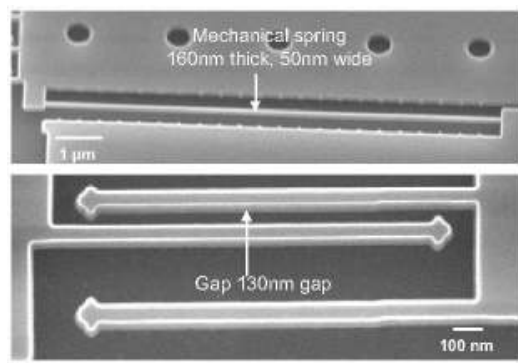

Figure 9. Elementary NEMS structures :thin mechanical beams and narrow gaps

After release, the static behaviour of these N-MEMS structures depends strongly on the design. The potential defaults, illustrated on Fig. 10, are substrate or lateral sticking and residual deflections due to stresses. Nevertheless, appropriate design is capable to limit this kind of problems. Lateral and vertical stiffnesses must be sufficient to avoid sticking problems. Limitation of large structures dimensions and flexible beams length allows to limit residual deflections.
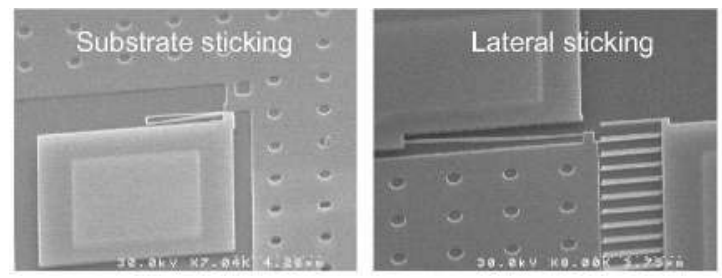

Figure 10. Examples of pøtential defaults encountered with NEMS structures These technologies have been used to manufacture thin SOI 50G IP and 50G OOP accelerometers (Fig. 11 \& 12). Fig. 13 presents SEM photograph of a thin SOI IP NEMS accelerometer.

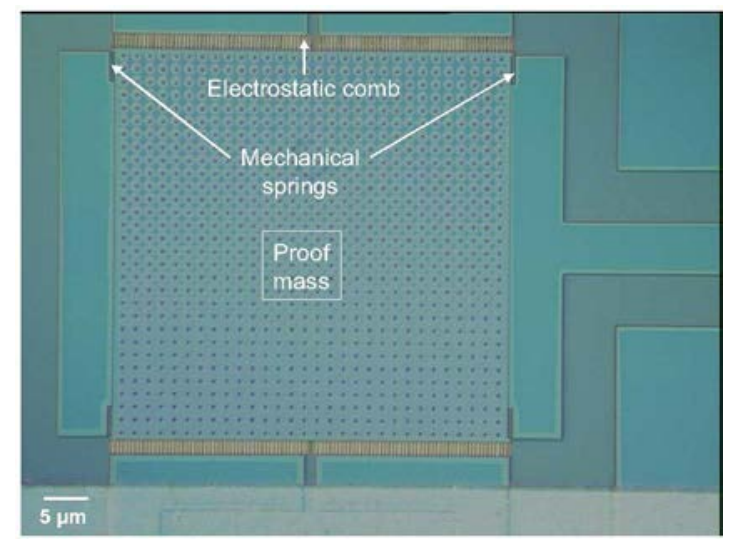

Figure 11. Ph॰t॰graph $\bullet$ thin SOI NEMS IP50G accelerømeter

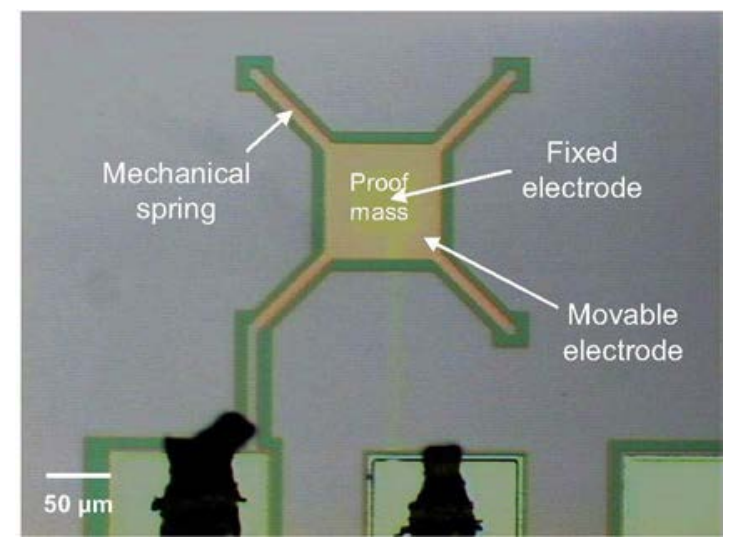

Figure 12. Ph॰tograph of thin SOI NEMS OOP50G accelerømeter

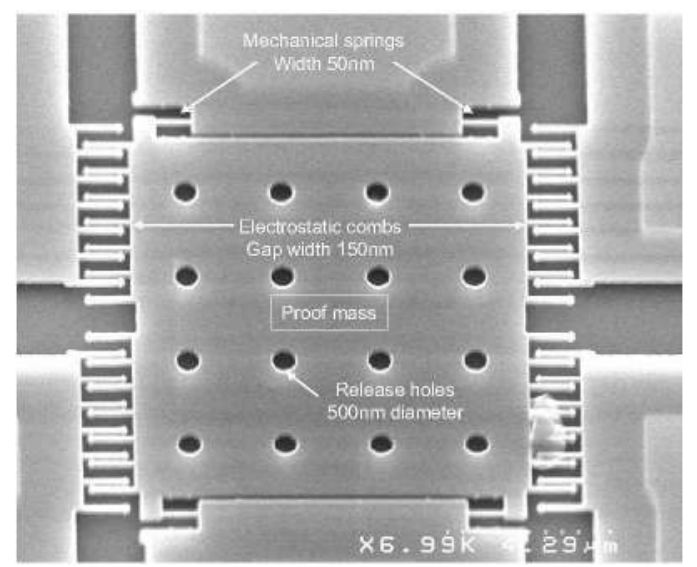

Figure 13. SEM ph॰t॰graph of thin SOI NEMS IP accelerømeter

\section{Characterization}

Characterization of devices including NEMS structures is really challenging because some dimensions are in the nano-scale. In 
addition, the structures are free standing and sometimes exhibit low stiffness. AFM technique has been investigated in order to provide measurement related to released NEMS structures. Specific procedures have been developed to solve the problems encountered, in particular to avoid breaking or instability occurring in case of low stiffness structures. AFM is used in tapping mode. This mode allows to limit mechanical interaction between the AFM tip and the NEMS measured. The oscillations are damped due to interaction between AFM tip and the surface in particular by Van der Waals forces. The cantilever is excited at resonance frequency $(50-300 \mathrm{kHz})$ with an amplitude of a few $10 \mathrm{~nm}$ and a control of the oscillation amplitude. The AFM tip must be chosen carefully by considering mechanical stiffness, resonance frequency, curvature radius. In addition imaging conditions must be optimized for NEMS measurement. In particular, the amplitude set point is fixed to ensure soft tapping, the scan rate is reduced to ensure low scanning speed and the $Z$ limit is fixed to ensure maximum vertical resolution. Vertical resolution is excellent (about A). Lateral resolution is limited by tip radius of curvature ( $\mathrm{a}$ few $\mathrm{nm}$ ). This AFM technique is now capable to provide information such as substrate/lateral sticking (Fig. 14). measurement of critical dimensions like cantilever beam vertical deflection and width (Fig. 15), with atomic resolution for vertical axis and a few $\mathrm{nm}$ for lateral resolution.

These techniques have been used to investigate and characterize the behaviour of fabricated thin SOI IP and OOP accelerometers. In particular vertical position of the mechanical structure after release process has been investigated in details. Fig. 16 and 17 show characterization results related to vertical residual deflections of free-standing IP50G and OOP50G accelerometers after the end of the process.
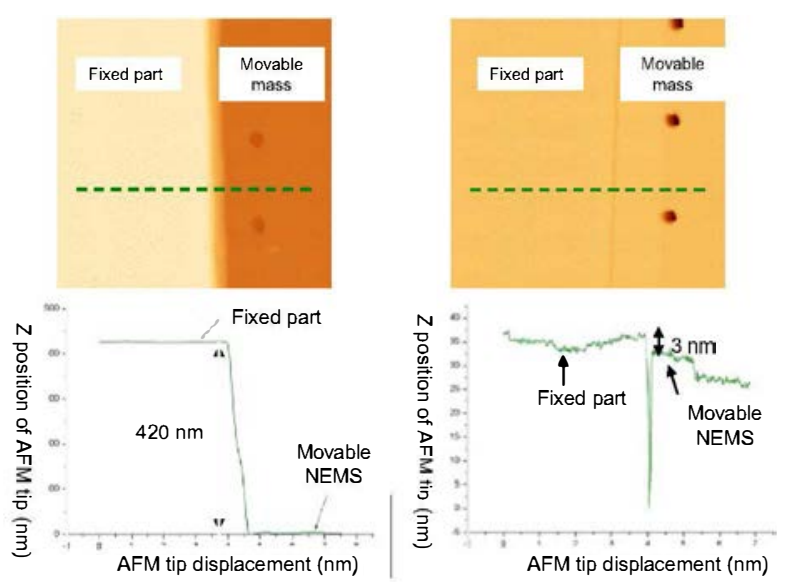

Figure 14. AFM images and measurement of relative vertical position of fixed and released structures, for sticking problem evaluation

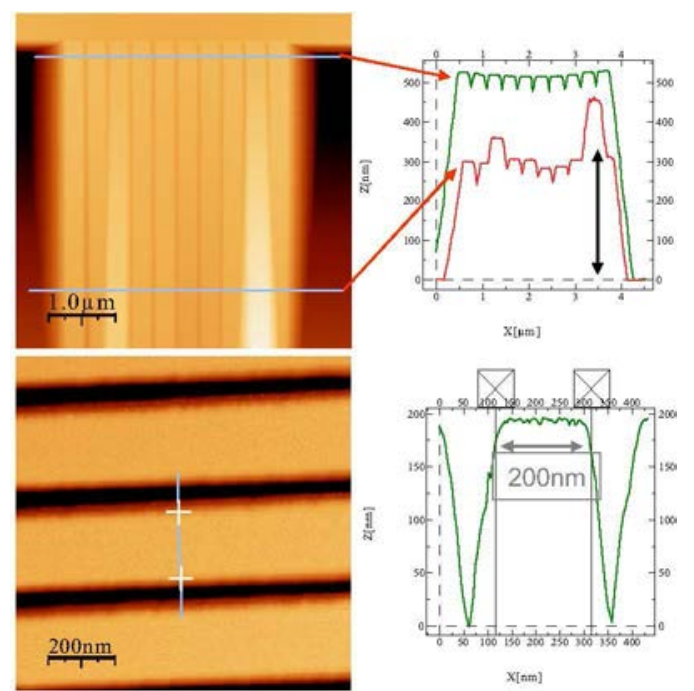

Figure 15. AFM characterization of first NEMS structures

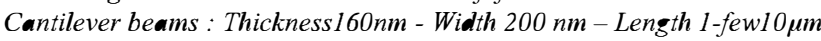

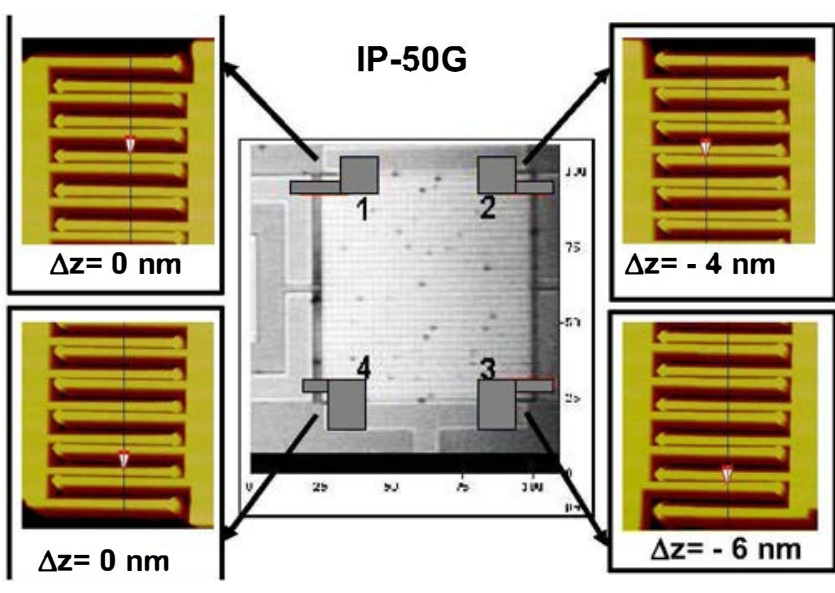

Figure 16. AFMcharacterization of IP 50 Gaccelerømeter $\Delta z$ : vertical misalignment of movable structure

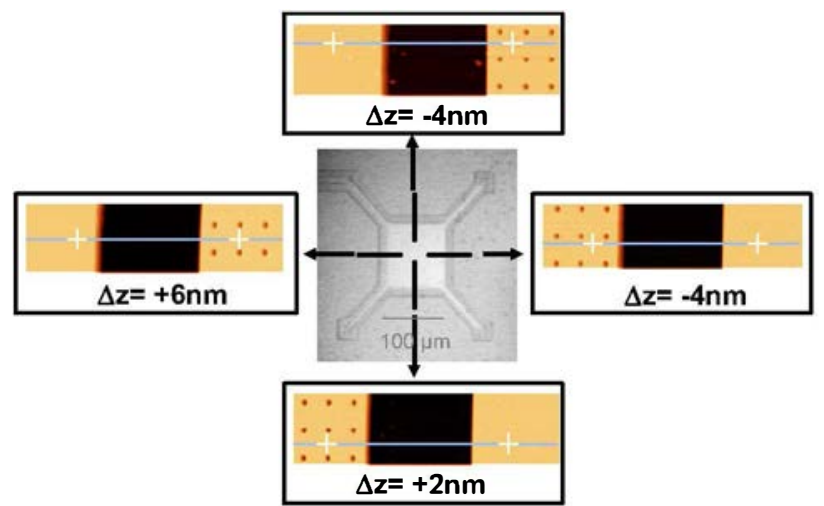

Figure 17. AFM characterization of OOP $50 \mathrm{G}$ accelerømeter $\Delta z$ : vertical misalignment of movable structure 
Figure 18 presents results of AFM measurements concerning vertical position of NEMS structures after release process for 50G IP and OOP accelerometers.

\begin{tabular}{|c|c|c|}
\hline $\begin{array}{l}\text { Type of } \\
\text { accelerometer }\end{array}$ & Characteristics & $\begin{array}{l}\text { Residual vertical } \\
\text { deflection }(\mathrm{nm})\end{array}$ \\
\hline \multirow{3}{*}{$\begin{array}{l}\text { In-Plane } \\
50 \mathrm{G}\end{array}$} & Electrostatic Gap 150nm & $<+/-6 \mathrm{~nm}$ \\
\hline & Mass $75 \times 75 \mu \mathrm{m}$ & \\
\hline & $\begin{array}{l}\text { Electrostatic Gap 130nm } \\
\text { Mass } 75 \times 150 \mu \mathrm{m}\end{array}$ & $<+/-11 \mathrm{~nm}$ \\
\hline $\begin{array}{l}\text { Out-of-Plane } \\
50 \mathrm{G}\end{array}$ & $\begin{array}{l}\text { Electrostatic Gap } 400 \mathrm{~nm} \\
\text { Mass } 100 \times 100 \mu \mathrm{m}\end{array}$ & $<+/-6 \mathrm{~nm}$ \\
\hline
\end{tabular}

Figure 18. "Static characterization" of thin SOI IP50G and OOP50G accelerometers : vertical residual deflection after release process

These results show that appropriate design and technology allow to fabricate IP-50G and OOP-50G thin SOI accelerometers exhibiting negligible vertical residual deflection after process compared to the $160 \mathrm{~nm}$ thickness.

In addition, "electro-mechanical" behaviour of NEMS submitted to driving voltage has been investigated. A line including a fixed part and a movable part is selected. Then images are realized for different actuation voltages. The main difficulty comes from the fact that AFM measurement is influenced by the electrical field created near the beam tip when a voltage is applied between different parts of the NEMS device.

Fig. 19 shows the first AFM characterization of displacement versus applied voltage obtained on a OOP 50G accelerometer submitted to an electrostatic force.
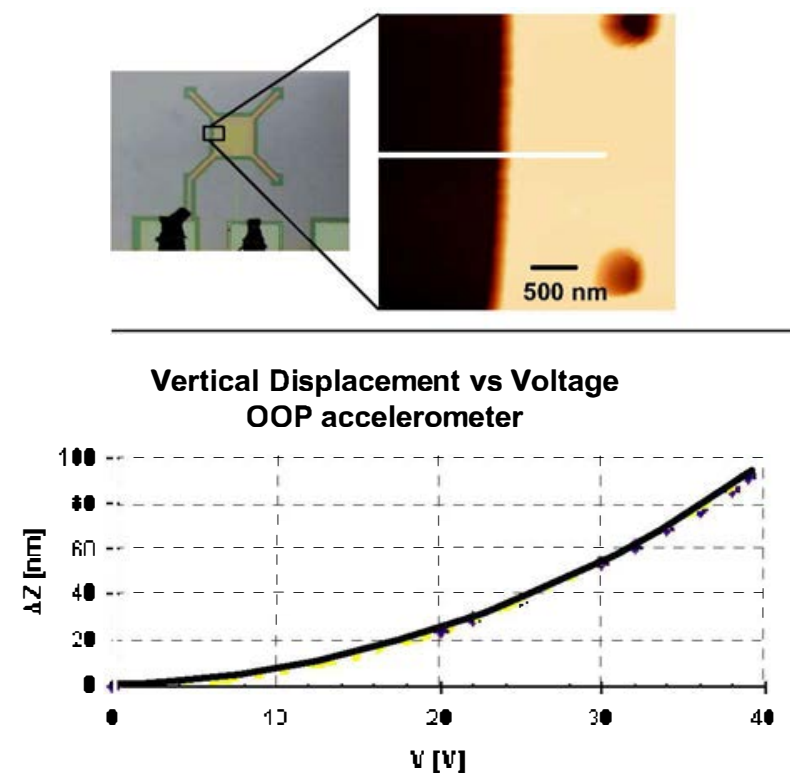

Figure 19. First result of "electro-mechanical characterization" of Thin SOI OOP $50 \mathrm{G}$ accelerometer
The deflection obtained under applied voltage is $90 \mathrm{~nm}(400 \mathrm{~nm}$ gap). This first result demonstrates the capability of AFM technique to provide characterizations of electro-mechanical behaviour of NEMS devices and shows the feasibility of electrostatic driving of our NEMS structures. This work is still on progress in order to improve the AFM measurement and have a better understanding of NEMS electro-mechanical behaviour.

\section{CONCLUSION}

First Thin SOI NEMS structures for accelerometers compatible with "In-IC" integration have been designed and fabricated in a thin $160 \mathrm{~nm}$ SOI layer in order to be compatible with $0.13 \mu \mathrm{m}$ CMOS SOI technology. IP and OOP configurations have been designed and fabricated. The modeling and design take into account specific phenomenon occurring in the nano-scale, in particular Casimir force. NEMS accelerometers with mechanical springs $50 \mathrm{~nm}$ wide, electrostatic gaps $130-400 \mathrm{~nm}$ wide have been fabricated thanks to the use of hybrid lithography combining e-beam and DUV lithography and also FH-vapor release to limit sticking problems. AFM techniques have been investigated and optimized to characterize NEMS structures and accelerometers. It has been shown that appropriate design and technology enable to fabricate devices exhibiting negligible residual deflections and good mechanical behaviour after process. In addition, AFM has been investigated for electromechanical characterizations of NEMS and accelerometers submitted to an actuation voltage. The deflection obtained with OOP accelerometers demonstrates the capability of AFM technique to provide this kind of characterizations and also the feasibility of electrostatic driving of our NEMS structures. Complementary characterizations are currently on progress in order to characterize electro-mechanical static and dynamic behaviour and also to investigate more in details limitations in performances.

\section{ACKNOWLEDGMENT}

Author acknowledges the support of European Commission for the funding of the integrated Project MIMOSA IST-2002-507045

\section{REFERENCES}

[1] M.L. Roukes, "Nanoelectromechanical systems", Solid State Sensor and Actuator Workshop, Proceedings pp. 529-551, South Carolina, June 4-8, 2000

[2] K.L. Ekinci, Y.T. Yang, M.L. Roukes, "Ultimate limits to inertial mass sensing based upon nanoelectromechanical systems", Journal of Applied Physics, V95, N5, pp. 2685-2689, March 2004

[3] J.D. Aldridge et al, "Nanoelectronic and nanomechanical systems", SPIE Proceedins 4591, 11, 2001

[4] http://www.mimosa-fp6.com

[5] P. Andreucci, L. Duraffourg, E. Ollier, V. Nguyen, M. T. Delaye, P. Robert, "Impact of Casimir force on nano accelerometers modeling", IEEE Sensors Conference 06, Daegu - Korea, 22-25 October, 2006 